\title{
Policy Modeling in Four Agent Economy
}

\author{
Adam Woźniak \\ Institute of Control and Computation Engineering \\ Warsaw University of Technology, \\ ul. Nowowiejska 15/19, 00-665 Warszawa, Poland \\ wozniak@ia.pw.edu.pl
}

\begin{abstract}
This paper proposes a simple model of policy game played by four main agents of economy: profit maximizing firms active on competitive market, monopolistic trade union (aggregated wage setters), government and central bank. The interactions between agents are described by the single period aggregate demand and supply equations. We also adopt assumption of bounded rationality of agents. After reduction of firms as active agent, the resulting three agents decision system is modeled as Stackelberg game with central bank as leader and trade union and government as composite follower, aggregated by means of Nash bargaining solution. The simulation of policy game is provided.
\end{abstract}

\section{Introduction}

Classical wisdom holds that, activity of conservative central bank, that is a central bank (CB) which places a greater weight on reduction of inflation than society, reduces equilibrium inflation with no (or very low) cost in terms of output. However, at the end of nineties, papers modeling decision process in the economy as policy game played within multiagent system, questioned desirability of conservative CB. For example V. Guzzo and A. Velasco concluded with proposition that decisions of central bank that pay little attention to price stabilization, so called populist CB, give better result because they lead to full employment, high output and low inflation in equilibrium [1], [2].

More complicated models of decision process used in the papers start with multiagent situation, but at the end describe the interactions among two agents only aggregate wage setters (trade union) and central bank. The objective functions of agents are chosen as quadratic and economy is modeled using Keynesian aggregate demand - aggregate supply framework. Within these models, the case for a populist central bank can be made when aggregated wage setters are inflation averse Stackelberg leader with respect to a central bank that controls inflation [3].

However, G. Ciccarone and E. Marchetti in their recent paper pointed out that hypothesis that workers' organizations are interested, besides real wages and employment, in inflation per se is difficult to prove [4]. The fulfillment of second assumption that trade unions act as leader, that is announce their decision in advance knowing the response function of central bank is also problematical. Third, the assumption that agents in modeled economy are perfectly rational and optimize quadratic functions has rather mathematical than case study research origin. This all is 
crucial because the presented results are not robust to removal of any from the above assumptions.

This paper aims at presentation of simple, but free from the above weakness, model of policy game played by four main agents of economy: profit maximizing firms active on competitive market, monopolistic trade union (aggregated wage setters), government and central bank. Their decision variables are the level of employment, $L$, the nominal wage, $W$, the budget deficit, $B$, and the supply of money, $M$, respectively. When the decisions are taken, the economy 'produces' in equilibrium state output, $Y$, and rate of inflation, $\Pi$.

The interactions between agents will be described by the single period aggregate demand and supply equations. We also adopt, to some extend, assumption of bounded rationality of agents.

\section{Interactions among Agents Constituting an Economy}

First, we assume that output (production), $Y$, is described by short-run production function

$$
Y=L^{\gamma} K^{1-\gamma}
$$

where $L$ is labor (level of employment), $K$ - capital, and $\gamma \in(0,1)$.

The first agent in our model is an aggregated one - all production firms active on competitive market. As mentioned, this agent always tends to maximize his (aggregate) profit

$$
Z=Y-L(W / P),
$$

where $P$ is given price level, choosing level of employment (labor demand) $L$. Therefore, his decision problem is as follows

$$
\text { find } L^{\circ}=\arg \max _{L}\left[L^{\gamma} K^{1-\gamma}-L(W / P)\right] \text {. }
$$

The solution of this problem is easy to obtain by differentiation and is the following

$$
L^{\circ}=\left(\gamma \frac{P}{W}\right)^{\frac{1}{1-\gamma}} K
$$

and takes the form of response function to external, for this agent, variables $P$ and $W$. The above equation is nonlinear and troublesome in use, so as is customary, we take natural logs and convert it into linear one

$$
l^{\circ}=-\frac{1}{1-\gamma}(w-p)+\frac{\ln \gamma}{1-\gamma}+k
$$

where small letters denote $\operatorname{logs}$, e.g., $k=\ln K$.

The assertion that firms are perfect rational and their behavior in any circumstances can be described by their best response (2) opens possibility to eliminate from further consideration activity of first agent described by decision problem (1) and using 'stiff' equation of labor demand (2) instead. Consequently the number of agents is reduced by one and we have the following explicit equation relating output (in logs) to wage and price level 


$$
y=\gamma l^{\circ}+(1-\gamma) k=-\frac{\gamma}{1-\gamma}(w-p)+\frac{\gamma}{1-\gamma} \ln \gamma+k
$$

In the sequel for simplicity, we shorthand the constant term to $y_{\mathrm{c}}=\frac{\gamma}{1-\gamma} \ln \gamma+k$, what leads to the following, so called, aggregate supply (AS) equation

$$
y=-\frac{\gamma}{1-\gamma}(w-p)+y_{\mathrm{c}} .
$$

It describes the aggregate supply of output by competitive profit-maximizing firms as decreasing when the wage is growing and increasing with the price level.

We assume that budget deficit $B$ is covered using monetary base; therefore, exchange equation has the form

$$
M+B=P Y .
$$

When we define $D=B / M$ the above equation changes to $M(1+D)=P Y$ or in logs

$$
y=m-p+\ln (1+D) .
$$

Because $D$ is generally less than 0.2 , we can linearize this equation to

$$
y=m+D-p .
$$

The equation (4) is called aggregate demand (AD) equation. It shows by making aggregate demand for output dependent upon money balance, the traditional inverse relationship, for a given money supply, between demand for output and price level.

As we remember, trade union, government and central bank are remaining agents in modeled economy. The level of inflation and unemployment occurs as the result of their decisions concerning levels of nominal wage, budget deficit and money supply. Therefore, we have to transform slightly our description and eventually add equation describing unemployment.

The inflation rate equals $\Pi=\left(P-P_{-1}\right) / P_{-1}=P / P_{-1}-1$. By assuming some "prior" level of prices, $P_{-1}$, we may talk of inflation and current prices interchangeably, cf. [5]. For convenience, we assume $P_{-1}=1$, so

$$
\Pi=P-1=\exp (p)-1 .
$$

Bearing above in mind, we can now transform equation (3) and (4) to the following form

$$
\begin{gathered}
y=\gamma(m+D-w)+(1-\gamma) y_{\mathrm{c}} \\
p=(1-\gamma)(m+D)+\gamma w-(1-\gamma) y_{\mathrm{c}} .
\end{gathered}
$$

The above equations describe how output, eq. (5), and inflation, eq. (6), depend on money supply, budget deficit and nominal wage.

Now, we will present equation, which describes unemployment. Let $N$ be a given level of labor force. When first agent (production firms) is rational, employment rate is equal $E=L^{\circ} / N$, in logs $e=l^{\circ}-n$. Under our assumptions it gives 


$$
e=\frac{1}{\gamma} y+\ln \gamma-\frac{1-\gamma}{\gamma} y_{\mathrm{c}}-n .
$$

Equation (7) means that unemployment rate $U=1-E$ decreases when output increases, so maximizing output means minimizing unemployment.

\section{Primal Decision Problems of Agents}

Basing on the above discussion of interactions in the economy, we can now define primal (isolated) decision problems of the remaining, active agents: trade union, government and central bank.

Usually one assumes that agents seek to optimize their objective functions, quadratic in variables, cf. [6]. This means that tacitly it is postulated, as in classical economics, that agents always succeed in choosing the best solution optimizing their functions. We adopted this assertion when concerned production firms on competitive market. Now we weaken it and will follow the way of H. Simon and assume that remaining agents interpret results as either satisfactory or unsatisfactory and that there exists an aspiration level (threshold) constituting the boundary between satisfactory and unsatisfactory. The agent, instead of seeking for the best alternative, looks for a good one only [7]. In other words, we assume that rationality of trade union, government and central bank is bounded and they are satisficing decision makers.

The classical thinking of organized labor asserts that the increase of wages is the main interest of trade union although it dislikes increase of unemployment. Although it is problematical, we assume that to some extend trade unions take into account requirement of keeping inflation on proper level.

Because we will state decision problem of trade union as maximization and keeping the above in mind we form the objective function of this agent as a weighted sum of real wage $W / P$, and terms measuring threshold violation

$$
\begin{gathered}
T U_{\mathrm{p}}=(w-p)+\alpha_{1} \min \left(0, y-y_{\mathrm{TU}}\right)-\alpha_{2} \max \left(0, \Pi-\Pi_{\mathrm{TU}}\right), \\
0<\alpha_{2}<\alpha_{1}<1, y_{\mathrm{TU}}=\gamma\left(e_{\mathrm{D}}+n-\ln \gamma\right)+(1-\gamma) y_{\mathrm{c}}, E_{\mathrm{D}}=1-U_{\mathrm{D}} .
\end{gathered}
$$

The signs of terms describing threshold violation are selected in such a way that first term is smaller than zero when output is smaller than its threshold $y_{\mathrm{TU}}$ calculated by trade union basing on accepted level of unemployment, $U_{\mathrm{D}}$, and second - is smaller than zero when inflation is larger than threshold $\Pi_{\mathrm{TU}}$.

The decision problem of trade union is now the following

$$
\begin{aligned}
& \text { find } w^{\circ}=\arg \max _{w} \geq_{0}[T U=(1-\gamma)(w-m-B(m) / \exp (m))+ \\
& \quad+\alpha_{1} \min \left(0, \gamma(m+B(m) / \exp (m)-w)+(1-\gamma) y_{\mathrm{c}}-y_{\mathrm{TU}}\right)+ \\
& \left.\quad-\alpha_{2} \max \left(0, \exp \left((1-\gamma)(m+B(m) / \exp (m))+\gamma w-(1-\gamma) y_{\mathrm{c}}\right)-1-\Pi_{\mathrm{TU}}\right)\right] .
\end{aligned}
$$

In the above problem constraint on minimal wage had to be added. For simplicity, we assumed that the minimal wage, $W_{\min }$, equals 1 .

Similar considerations lead to objective function of government

$$
G_{\mathrm{p}}=\beta_{1} \min \left(0, B-B_{\mathrm{G}}\right)+\beta_{2} \min \left(0, y-y_{\mathrm{G}}\right)-\beta_{3} \max \left(0, \Pi-\Pi_{\mathrm{G}}\right), \beta_{1}, \beta_{2}, \beta_{3}>0
$$

and the decision problem of this agent 


$$
\text { find } \begin{aligned}
B^{\circ} & =\arg \max _{B}\left[G=\beta_{1} \min \left(0, B-B_{\mathrm{G}}\right)+\right. \\
& +\beta_{2} \min \left(0, \gamma(m+B / \exp (m)-w)+(1-\gamma) y_{\mathrm{c}}-y_{\mathrm{G}}\right)+ \\
& \left.+\beta_{3} \max \left(0, \exp \left((1-\gamma)(m+B / \exp (m))+\gamma w-(1-\gamma) y_{\mathrm{c}}\right)-1-\Pi_{\mathrm{G}}\right)\right] .
\end{aligned}
$$

Ending modeling of agents' interests, we adopt as the objective function of the last agent (central bank) the function depending on terms measuring inflation and output (unemployment) target missing

$$
C B_{\mathrm{p}}=-\max \left(0, \Pi-\Pi_{\mathrm{CB}}\right)+\delta \min \left(0, y-y_{\mathrm{CB}}\right), \delta>0 .
$$

The decision problem of central bank is stated as

$$
\text { find } \begin{aligned}
m & =\arg \max _{m}[C B= \\
& =-\max \left(0, \exp \left((1-\gamma)(m+B(m) / \exp (m))+\gamma w-(1-\gamma) y_{\mathrm{c}}\right)-1-\Pi_{\mathrm{CB}}\right)+ \\
& \left.+\delta \min \left(0, \gamma(m+B(m) / \exp (m)-w)+(1-\gamma) y_{\mathrm{c}}-y_{\mathrm{CB}}\right)\right] .
\end{aligned}
$$

This completes descriptive part of our model - description of agents' decision problems with their decision instruments and interactions joining them. Now we must model the rules (protocol) regularizing behavior of agents. In other words, we must describe cooperation-coordination mechanism in economy. We assume that central bank is independent in his decisions and acts first announcing chosen supply of money. Knowing level of this external variable trade union and government negotiate level of wage and budget deficit. As a result, equilibrium determined by aggregate demand and aggregate supply equations (3), (4) gives employment, output and inflation.

\section{Cooperation-Coordination Mechanism}

The assumption about trade union-government negotiations is typical. As mechanism of negotiations, we propose concession mechanism derived by F. Zeuthen in his book devoted to this topic [8]. We adopted this mechanism because of two reasons. From one side, it is a dynamic adjustment procedure modeling real negotiations. From the other side, starting from the work of Harsanyi [9], it is known that this procedure converges to axiomatic Nash bargaining solution. We are not interested in presentation details of Zeuthen process here, short description can be found, e.g. in [10]. As we will see, convergence to relatively easy computable Nash bargaining solution significantly simplifies description of central bank operation rules.

On the first gland, central bank right to the first move gives him some kind of supremacy. But from the hierarchical games theory it is known that, so called leader, has supremacy only when he has appropriate information about the other agents, followers, giving him also information priority [11].

When we assume that presented model, trade union and government primal decision problems included, is known to the central bank, together with information that his partners tend in negotiation to the Nash bargaining solution, we can say that he has this priority. Both above assumptions seem quite reasonable.

The bestowal of right to the first move and information priority on central bank enables to model his decision situation as Stackelberg game with bank as leader and 
trade union and government as composite follower, aggregated by means of Nash bargaining solution.

The essential tool in analyzing Stackelberg game is response mapping of follower. Let $\left(w^{N}, B^{\mathrm{N}}\right)$ denotes Nash bargaining solution to union - government negotiation. For given level of money supply $m$, having information priority, central bank is able to compute $r(m)=\left(w^{\mathrm{N}}(m), B^{\mathrm{N}}(m)\right)$ solving the following nonlinear optimization problem (cf. [12])

$$
\begin{gathered}
r(m)=\left(w^{\mathrm{N}}(m), B^{\mathrm{N}}(m)\right)=\left(T U^{-1}(m, \cdot, \cdot)\left(s_{1}(m)\right), G^{-1}(m, \cdot, \cdot)\left(s_{2}(m)\right)\right), \\
\left(s_{1}(m), s_{2}(m)\right)=\arg \max _{\left(s_{1}, s_{2}\right) \in S_{\mathrm{d}}(m)}\left(s_{1}-s_{1}{ }^{\mathrm{d}}\right)\left(s_{2}-s_{2}{ }^{\mathrm{d}}\right)
\end{gathered}
$$

where

$$
\begin{gathered}
S_{\mathrm{d}}(m)=S(m) 3\left\{\left(s_{1}, s_{2}\right) \mid s_{i} \geq s_{i}^{\mathrm{d}}, i=1,2\right\}, \\
S(m)=\left\{\left(s_{1}, s_{2}\right) \mid(\exists w \geq 0)(\exists B)\left(s_{1}=T U(m, w, B) \wedge s_{2}=G(m, w, B)\right)\right\}
\end{gathered}
$$

and $\left(s_{1}{ }^{\mathrm{d}}, s_{2}{ }^{\mathrm{d}}\right)$ is known status quo (disagreement) point.

We recall that $T U$ and $G$ denote functions maximized in trade union (9) and government (11) decision problem, respectively. Of course, it is impossible to solve the problem (14) analytically, but for given set $\left\{m_{j}\right\}$ of money supplies, central bank is able to compute set of responses $\left\{r\left(m_{j}\right)\right\}$ and basing on both sets, to estimate response function ${ }^{1}$

$$
m \rightarrow r(m)=\left(w^{\mathrm{N}}(m), B^{\mathrm{N}}(m)\right) .
$$

Now the decision problem of central bank takes the form

$$
\begin{aligned}
& \text { find } m^{\circ}=\arg \max _{m}[C B S(m)= \\
& \quad-\max \left(0, \exp \left((1-\gamma)\left(m+B^{\mathrm{N}}(m) / \exp (m)\right)+\gamma w^{\mathrm{N}}(m)-(1-\gamma) y_{\mathrm{c}}\right)-1-\Pi_{\mathrm{CB}}\right)+ \\
& \left.\quad+\delta \min \left(0, \gamma\left(m+B^{\mathrm{N}}(m) / \exp (m)-w^{\mathrm{N}}(m)\right)+(1-\gamma) y_{\mathrm{c}}-y_{\mathrm{CB}}\right)\right] .
\end{aligned}
$$

That is the reformulation of problem (13) using defined response function.

It is worth noting, that central bank knows only estimate of function $m \rightarrow C B S(m)$ maximized in his decision problem, so called composite objective function. However, as we remember, the problem of central bank was stated in fact, not as optimization but satisficing one (assumption about bounded rationality). So somewhat blurred description of composite objective function do not prevent this agent from taking suitable, satisfactory decision, which will give desired proper level of inflation and output.

\section{Simulation Result}

Now, we present simulation results of modeling hypothetical closed economy with described four agents. We adopt the following values of parameters:

- for production function: $\gamma=0.7, y_{\mathrm{c}}=6.3(K=1251.7)$;

- for primal decision problem of trade union: weight of output $\alpha_{1}=0.6$, output threshold $y_{\mathrm{TU}}=6.55$, weight of inflation $\alpha_{2}=0.3$, inflation threshold $\Pi_{\mathrm{TU}}=0.1$ (rather modern trade union);

1 Equation (14) defines function, only when we assume that $\left(w^{\mathrm{N}}(m), B^{\mathrm{N}}(m)\right)$ is unique for every $m$. 
- for primal decision problem of government: deficit threshold $B_{\mathrm{G}}=40$, weight of deficit $\beta_{1}=10$, output threshold $y_{\mathrm{G}}=6.5$, weight of output $\beta_{2}=0.6$, weight of inflation $\beta_{3}=0.7$, inflation threshold $\Pi_{\mathrm{G}}=0.08$;

- for primal decision problem of central bank: inflation threshold $\Pi_{\mathrm{CB}}=0.05$, output threshold $y_{\mathrm{CB}}=6.3$, weight of output $\delta=0.2$ (rather conservative central bank).

The status quo point was calculated basing on Nash equilibrium in noncooperative game of trade union and government: $\left(s_{1}{ }^{\mathrm{d}}, s_{2}{ }^{\mathrm{d}}\right)=(-0.235211,-0.159484)$.

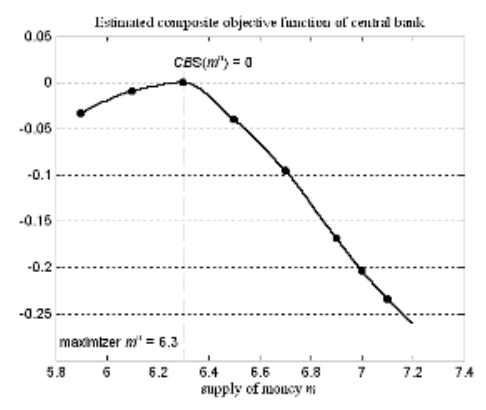

Fig. 1.

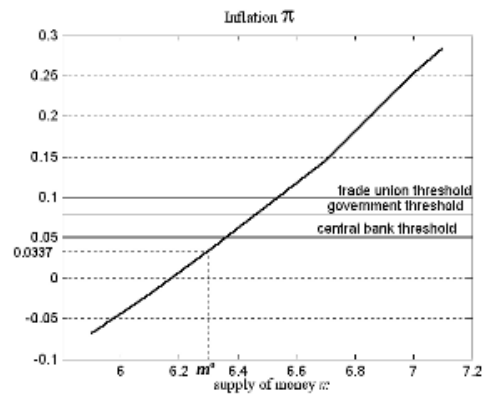

Fig. 2.

The shape of estimated composite function $C B S(\cdot)$ is shown in the Fig 1 . Its maximal value equals zero and is realized by supply of money $m^{\circ}=6.3$. The resulted equilibrium state of modeled economy is presented above and in the following figures. The goals of central bank are met - inflation is below and output is above threshold. However, economic development is below trade union and government expectations: $Y^{\circ}=588.0$, compared to thresholds $Y_{\mathrm{TU}}=699.2$ and $Y_{\mathrm{G}}=665.1$. Therefore, employment is also below expectations $\left(L^{\circ}=425.4\right.$ compared to $L_{\mathrm{TU}}=$ 544.8 and $L_{\mathrm{G}}=507.3$ ). Separate analysis has showed that for given values of parameters the maximal attainable value of the real wage is slightly greater than one. As a consequence obtained value of real wage $(W / P)^{\circ}=0.97$ is satisfactory.

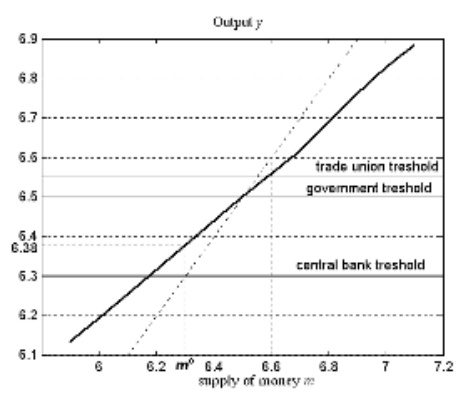

Fig. 3.

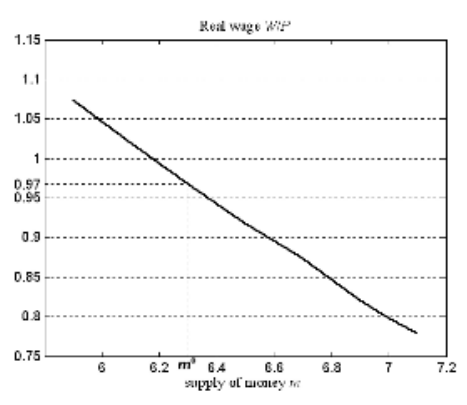

Fig. 4.

To complete analysis of simulation result, let us note that for $m=6.4$, inflation is 0.06 which is still below government and trade union expectations, and economy gives output $Y=626.2$ (compared to 588.0), employment $L=465.4$ (compared to 
425.4 , increase by $9.4 \%)$ and real wage $(W / P)=0.94$. It means that the adopted objective function of central bank with small weight of term assigned to output, characterizes, as we anticipated, conservative money authority.

\section{Conclusions}

The presented simulation result is the first attempt at using described model. It comes off well. The further research will be concentrated first, on examining of different parameter combination influence on result. Next, after tuning model, different literature hypotheses about connections between preference of agents modeled by their objective functions and outcomes will be checked.

\section{References}

1. Guzzo, V., Velasco, A.: The case for a populist central banker. European Economic Review, 43 (1999) 1317 - 1344

2. Guzzo, V., Velasco, A.: Revisiting the case for a populist central banker: A comment. European Economic Review, 46 (2002) 613 - 621

3. Jerger, J.: How strong is the case for a populist central banker? A note. European Economic Review, 46 (2002) 623 - 632

4. Ciccarone, G., Marchetti, E.: Trade unions' objectives and inflation. Public Economics Department, University of Rome La Sapienza, unpublished paper (2002)

5. Cubitt, R.P.: Corporatism, monetary policy and macroeconomic performance: a simple game theoretic analysis. Scandinavian Journal of Economics, 97 (1995) 245 - 259

6. Acocella, N., Di Bartolomeo, G.: Non-neutrality of monetary policy in policy games. Public Economics Department, University of Rome La Sapienza, Working Paper n. 49 (2002)

7. Simon, H.A.: A behavioral model of rational choice. Quarterly Journal of Economics, 69 (1955) $99-118$

8. Zeuthen, F.: Problems of Monopoly and Economic Warfare. Routledge \& Kegan, London (1930)

9. Harsanyi, J.C.: Approaches to the bargaining problem before and after the theory of games. Econometrica, 24 (1956) 144 - 156

10. Ren, Z., Anumba, C.J., Ugwu, O.O.: The development of a multi-agent system for construction claims negotiation. Advances in Engineering Software, 34 (2003) 683 - 696

11. Germeyer, Yu.B.: Igry s neprotivopolozhnymi interesami (Games with Non-antagonistic Interests). Nauka, Moskva (1976)

12. Nash, J.F.: The bargaining problem. Econometrica, 18 (1950) 155 - 162 